\title{
STUDY ON MORPHOLOGICAL VARIABILITY OF SACRAL BONES
}

\author{
Rachita Laxmikant Malwatkar1, Yuvaraj Jayprakash Bhosale ${ }^{2}$
}

${ }^{1}$ Assistant Professor, Department of Anatomy, Raipur Institute of Medical Sciences, Raipur.

${ }^{2}$ Additional Professor, Department of Anatomy, Seth G. S. Medical College and KEM Hospital, Parel, Mumbai.

\section{ABSTRACT}

Anatomical variations in the sacral bones are clinically important, while administering local anaesthetic agents in caudal block. The present study is a posthumous examination of variation in sacral bones from a tertiary care medical college.

\section{MATERIALS AND METHODS}

A total of 107 complete, undamaged dry sacral bones were analysed for the following parameters: Shape, length, transverse width, antero-posterior diameter of sacral hiatus; Location of the apex and base of sacral hiatus in relation to level of sacral vertebra; Distance from the apex and base of sacral hiatus to the level of S2 spine; Distance between the two superior ends of lateral sacral crests; Distance between right and left superior end of lateral sacral crest and the apex of sacral hiatus; Variations such as sacralisation of lumbar vertebra, dorsal deficient wall and agenesis of sacral hiatus.

\section{RESULTS}

The most commonly observed shape was inverted U (38.31\%), majority of the bones had sacral hiatus at the level of S4 (66\%) while the base of the hiatus at S5 (89\%). Mean (SD) (in mm) length of sacral hiatus was 22.5 (9.1), width was 15.16 (3.15) and anteroposterior diameter was 4.18 (1.07). Mean (SD) of distance (in mm) between S2 spine and the apex of sacral hiatus was 38.15 (9.4) and base was $60.3(9.2)$.

\section{CONCLUSION}

We found out a huge variability in the shape, location and dimensions of sacral bones and sacral hiatus. It is important for the clinicians to keep in mind this variability while performing caudal epidural block.

\section{KEYWORDS}

Posthumous, Vertebra, Variation.

HOW TO CITE THIS ARTICLE: Malwatkar RL, Bhosale YJ. Study on morphological variability of sacral bones. J. Evolution Med. Dent. Sci. 2016;5(65):4606-4609, DOI: 10.14260/jemds/2016/1050

\begin{abstract}
INTRODUCTION
Sacrum meaning 'Temple' in Greek and 'Sacred' in Latin is a large vertebral bone housing all the caudal spinal nerves. ${ }^{1}$ Sacral hiatus, the caudal opening of the sacral canal contains lower sacral and coccygeal nerve roots, filum terminale externa and fibro-fatty tissue. Due to imperfect development of laminae, the dorsal wall of the sacra is variably deficient. ${ }^{2}$ Sacral hiatus is clinically important as caudal block, also known as caudal epidural anaesthesia, is a commonly undertaken procedure carried out either for the management of chronic back pain or while doing major abdominal surgeries. Crucial to the administration of local anaesthesia is the identification of location of sacral hiatus for easy access into sacral epidural space and the attempt in doing so was carried out first time in 1941. ${ }^{3}$ Studies had evaluated the anatomical variation of sacral bone and came up with varying findings. ${ }^{4,5}$ Hence, we envisaged the present study to assess the morphometrical variation of the sacrum that may have an impact on the clinical significance during the administration of epidural anaesthesia.
\end{abstract}

Financial or Other, Competing Interest: None

Submission 19-07-2016, Peer Review 02-08-2016,

Acceptance 04-08-2016, Published 12-08-2016.

Corresponding Author:

Dr. Yuvaraj Jayprakash Bhosale,

Additional Professor,

Department of Anatomy,

Seth GS Medical College and KEM Hospital,

Parel, Mumbai-400012.

E-mail: dryuvaraj@gmail.com

DOI: $10.14260 /$ jemds/2016/1050

\section{MATERIALS AND METHODS}

The study was conducted in the Department of Anatomy, Seth GS Medical College and KEM Hospital, Mumbai, after obtaining review exemption from the Institutional Ethics Committee. A total of 107 complete, undamaged dry sacral bones that were undetermined gender and age were obtained and were kept free from any dust, moth or insect. Anatomical measurements were taken on these specimens using a steel scale, measuring tape, divider, goniometer, compass, 60-degree square and protractor (Fig. 1, 2 and 4). Since the posterior superior iliac spines, which are readily palpable on the body surface of the patient, imposed on the superolateral sacral crests of the sacrum and our measurements were carried out on dry sacral bones, the latter points were used as landmarks in the measurements. As the dural sac terminates around the level of S2, the distance from apex and base of the sacral hiatus to the level of the S2 spine was also measured. The following parameters were estimated for each sacral bone: Shape of sacral hiatus; Location of the apex of sacral hiatus in relation to level of sacral vertebra; Location of the base of sacral hiatus in relation to level of vertebra; Length of sacral hiatus; Transverse width of sacral hiatus; Anteroposterior diameter of sacral hiatus at the apex; Distance from the apex of sacral hiatus to the level of S2 spine; Distance from the base of sacral hiatus to the level of S2 spine; Distance between the two superior ends of lateral sacral crests; Distance between right superior end of lateral sacral crest and the apex of sacral hiatus; Distance between left superior end of lateral sacral crest and the apex of sacral hiatus; Variations such as sacralisation of lumbar vertebra, dorsal deficient wall and 
agenesis of sacral hiatus. Descriptive statistics was used for representing each of the above mentioned parameters.

\section{RESULTS}

Of the total 107 sacra three showed agenesis of sacral hiatus (Fig. 3G), two showed dorsal deficient wall (Fig. 3H) and two showed dorsal deficient wall and unfused sacral vertebrae. These seven sacra were included only for studying the shape of sacral hiatus and were excluded from the study for evaluation of rest of the parameters.

\section{Shape of Sacral Hiatus}

The most common shape observed was inverted U (Fig. 3A) and V (Fig. 3B), which was present in 41/107 (38.31\%) sacra and in 28/107 (26.16\%) sacra respectively. Table 1 lists the number of other shapes of sacral bones that were observed in the present study. Both the above types were considered as normal and the sacral hiatus was present against $5^{\text {th }}$ and $4^{\text {th }}$ sacral segments. Agenesis of sacral hiatus, a rare phenomenon was observed in 3 (2.8\%) specimens only (Fig. 3G).

\section{Location of Apex and Base of Sacral Hiatus}

Location of the apex of sacral hiatus in relation to level of sacral vertebra varied from S2 to S5 vertebra level. A large majority of the bones had the sacral hiatus at the level of S4 vertebra $(66 / 100)$ followed by S3 vertebra (31/100), S5 (2/100) and S2 (1/100). Similarly, location of the base of sacral hiatus in relation to level of vertebra varied from S4 vertebra to coccyx. A total of 89/100 had the base against S5 vertebra and was found against $S 4$ vertebra in 8/100 sacra and against coccyx in $3 / 100$ bones.

\section{Dimensions of Sacral Hiatus}

Mean (SD) Length (mm) of sacral hiatus was 22.5 (9.1) with a range between 10 and 50. Mean (SD) transverse width (mm) of sacral hiatus at its base was 15.16 (3.15) and ranged between 6 and $23 \mathrm{~mm}$. The anteroposterior diameter of sacral hiatus at its apex varied from 2-7 mm with the mean (SD) of 4.18 (1.07) $\mathrm{mm}$. Mean (SD) of distance (in $\mathrm{mm}$ ) between S2 spine and the apex of sacral hiatus was 38.15 (9.4), while the same for the base of sacral hiatus was $60.3(9.2) \mathrm{mm}$. The distance between two superior ends of lateral sacral crests varied from 50-85 mm with a mean (SD) of 65 (5.7) mm. Mean (SD) of the angle (in ${ }^{\circ}$ ) between the $9^{\text {th }}$ and $10^{\text {th }}$ parameters was $57.27(5.6)$, while for $9^{\text {th }}$ and $11^{\text {th }}$ parameter was 57.23 (6.1).

\begin{tabular}{|c|c|c|}
\hline Sl. No. & Shape of Sacral Hiatus & n (\%) \\
\hline 1 & Inverted U & $41(38.31)$ \\
\hline 2 & Inverted V & $28(26.16)$ \\
\hline 3 & M shaped & $12(11.21)$ \\
\hline 4 & Dumbbell & $11(10.28)$ \\
\hline 5 & Irregular & $5(4.67)$ \\
\hline 6 & Bifid & $3(2.8)$ \\
\hline 7 & Dorsal Deficient Wall & $4(3.73)$ \\
\hline 8 & Agenesis of Sacral Hiatus & $3(2.8)$ \\
\hline \multicolumn{2}{|c|}{ Table 1: Shapes of Sacral Vertebra (N=107) } \\
\hline
\end{tabular}

\begin{tabular}{|c|c|}
\hline Study ID & Key Findings \\
\hline $\begin{array}{c}\text { Nagashree et } \\
\text { al }^{4}\end{array}$ & $\begin{array}{l}\text { - } 51 \text { dry human sacral bones were } \\
\text { studied. } \\
\text { 23.5\% were inverted 'U' shaped, } \\
39.2 \% \text { inverted 'V' shaped, } 25.4 \% \\
\text { elongated, 9.8\% irregular and } 1.9 \% \\
\text { had complete agenesis. } \\
\text { The level of apex of sacral hiatus was } \\
\text { commonly found against 4th sacral } \\
\text { vertebra level in } 56 \% \text {. } \\
\text { The level of base of sacral hiatus was } \\
\text { commonly found against 5th sacral } \\
\text { vertebra. } \\
\text { The mean length of sacral hiatus was } \\
21.5 \text { mm. }\end{array}$ \\
\hline $\begin{array}{c}\text { Dhananjay et } \\
\text { al }^{5}\end{array}$ & $\begin{array}{l}\text { - } 103 \text { dry human sacral bones were } \\
\text { studied. } \\
\text { Agenesis of the hiatus was observed in } \\
3 \text { bones. } \\
\text { - Mean (SD) length of the sacral hiatus } \\
\text { was } 34.13 \text { (11.82) mm (Range 7-76 } \\
\text { mm). } \\
\text { Mean (SD) of width of sacral hiatus at } \\
\text { level of sacral cornua was } 13.71 \text { (2.24) } \\
\text { mm (Range 9-20 mm). }\end{array}$ \\
\hline $\begin{array}{c}\text { Shewale et } \\
\mathrm{al}^{6}\end{array}$ & 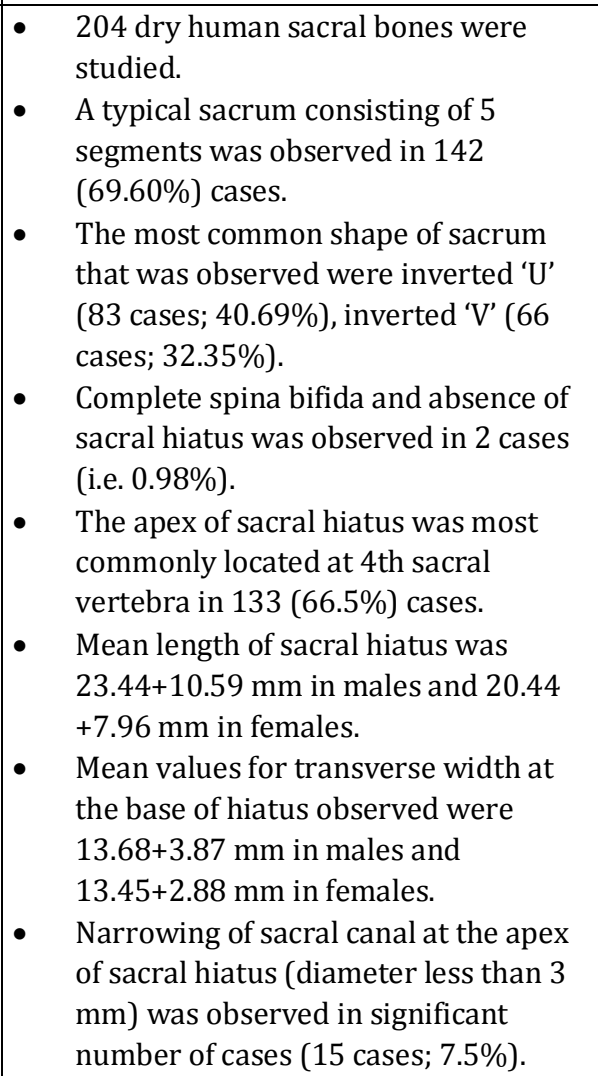 \\
\hline $\begin{array}{l}\text { Shinde } \\
\text { et al }{ }^{7}\end{array}$ & $\begin{array}{l}\text { - } 100 \text { dry human sacra were studied. } \\
\text { The inverted U shaped sacral hiatus } \\
\text { was the most common ( } 56 \%) \\
\text { followed by inverted V shaped sacral } \\
\text { hiatus in } 24 \% \text { of sacra. } \\
\text { The other variations like irregular } \\
\text { shaped hiatus (10\%), bifid hiatus } \\
\text { (2\%), dumbbell shaped hiatus (5\%), } \\
\text { complete spina bifida (1\%) and absent }\end{array}$ \\
\hline
\end{tabular}




\begin{tabular}{|c|c|}
\hline & $\begin{array}{l}\text { hiatus (2\%) were also observed by the } \\
\text { authors. }\end{array}$ \\
\hline Desai et al 8 & $\begin{array}{l}\text { - } 271 \text { dry human sacra studied. } \\
\text { The most commonly observed shape } \\
\text { of sacral bone was inverted U-shape } \\
(42.12 \%) \text { followed by inverted V- } \\
\text { shape (35.43\%), irregular (12.99\%). } \\
\text { - The mean length of sacral hiatus was } \\
21.70 \mathrm{~mm} \text {. } \\
\text { - The mean anteroposterior diameter of } \\
\text { sacral canal at the apex of sacral } \\
\text { hiatus was } 5.50 \mathrm{~mm} \text {. }\end{array}$ \\
\hline $\begin{array}{l}\text { Sasikala et } \\
\text { al }^{9}\end{array}$ & $\begin{array}{l}\text { - } \quad 30 \text { human dry sacra studied. } \\
\text { - } 80 \% \text { of the sacra had } 5 \text { segments, } 10 \% \\
\text { had } 6 \text { segments, } 6.7 \% \text { had } 4 \text { segments } \\
\text { and } 3.3 \% \text { had spina bifida. } \\
\text { - } 53.3 \% \text { were inverted ' } U \text { ' shaped, } \\
\text { 36.7\% were inverted 'V' shaped. } \\
\text { Apex of sacral hiatus was present at } \\
\text { the level of S4 in } 72.4 \% \text { and at S5 in } \\
\text { 20.7\% of bones. }\end{array}$ \\
\hline Table 2: Su & $\begin{array}{l}\text { nary of Key Findings from Similar Studies } \\
\text { in the Same Population }\end{array}$ \\
\hline
\end{tabular}

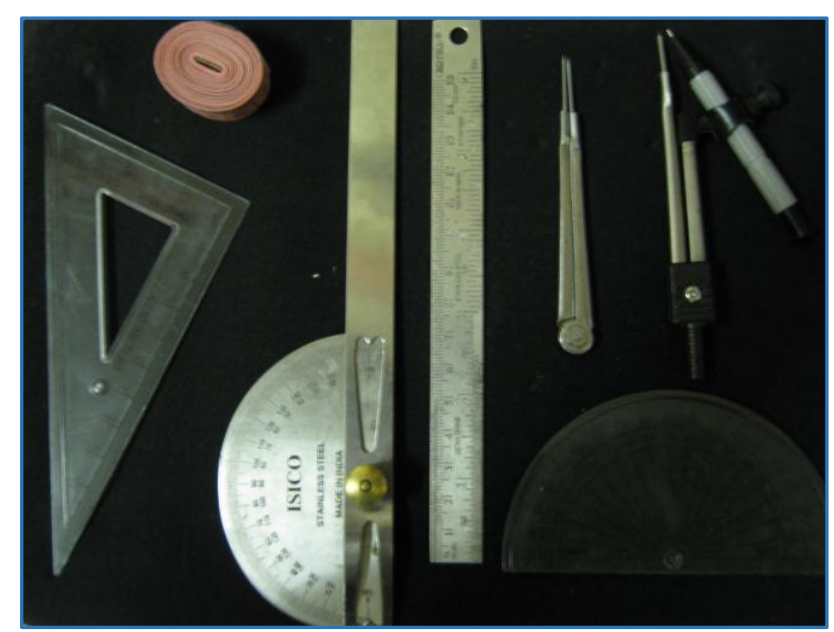

Fig. 1: Illustration showing the Instruments Used for the Study Set Square, Measuring Tape, Goniometer, Steel Scale, Divider, Compass, Protractor

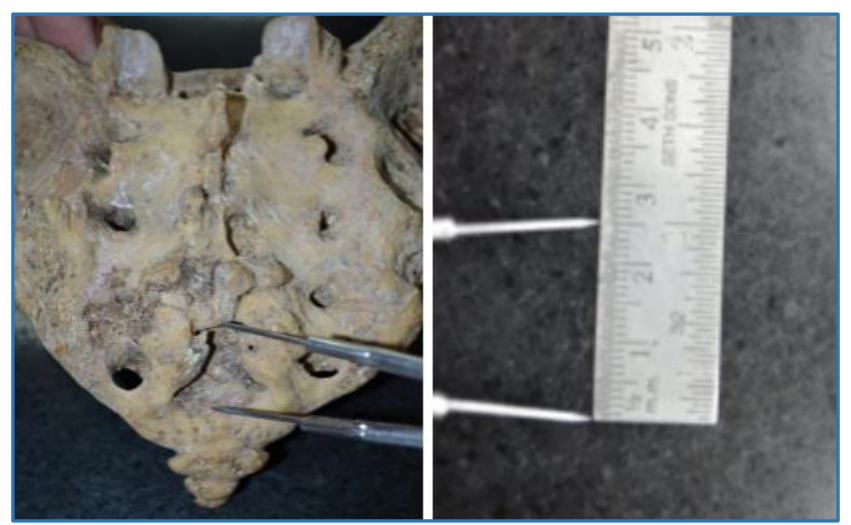

Fig.2: Illustration showing Measurement of Length of Sacral Hiatus
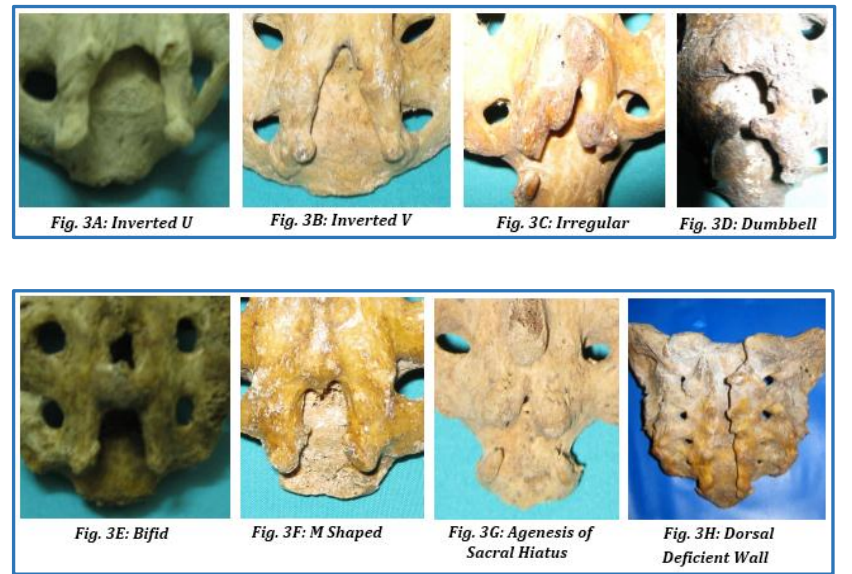

Fig. 3: Variations in Shapes of Sacral Hiatus

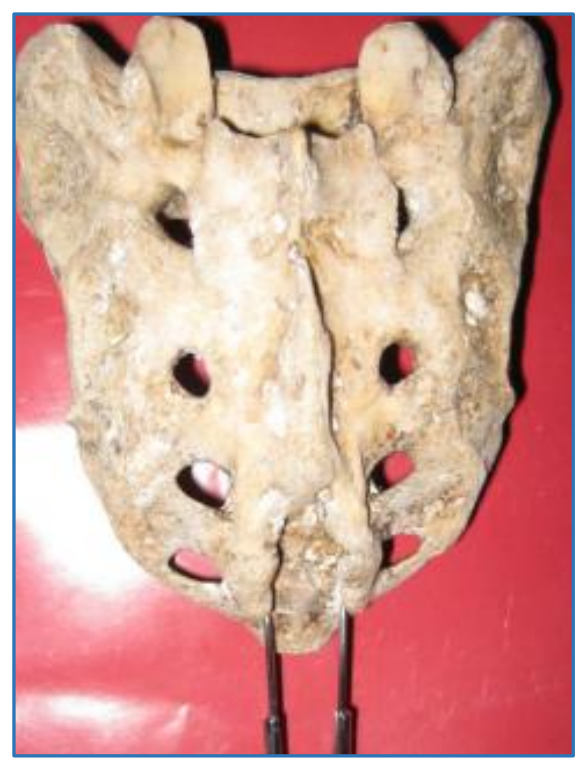

Fig. 4: Illustration showing Measurement of Transverse Width of Sacral Hiatus

\section{DISCUSSION}

The present study was undertaken to assess the variability in the shape, location and dimensions of sacra in 107 sacral bones. We found that the most commonly observed shape was inverted U (38.31\%), majority of the bones had sacral hiatus at the level of S4 (66\%), while the base of the hiatus was located at S5 vertebra (89\%). Mean (SD) length of sacral hiatus was 22.5 (9.1) $\mathrm{mm}$, while the width was 15.16 (3.15) $\mathrm{mm}$.

The sacra, bone articulates with the coccyx caudally and the wide base which lies superiorly binds to the fifth lumbar vertebra and forms a lumbosacral angle. It is set obliquely and curved longitudinally, its dorsal surface being convex, the pelvic concave. Usually, the fifth inferior articular process of sacrum is connected to the coccygeal cornua by intercornual ligaments and forms the sacral hiatus. But a huge anatomical variation has been observed and has been reported by various authors. Table 2 enlists the key findings of studies that had evaluated a similar hypothesis.

The success of caudal epidural block depends on the correct identification of the sacral hiatus and caudal epidural space. Significant unidentified anatomical variations in the same would lead to failure in delivering the anaesthetic agents. Usually, the patient is kept in prone position and then the cornua is palpated and then the spinal needle is inserted $2-3$ 
$\mathrm{mm}$ at an angle of 45 degrees through sacrococcygeal ligament. Reports state a failure rate of nearly $5 \% 10$ and a much higher $(14.83 \%)$ in children. ${ }^{11}$ Recently, various strategies such as using low-current epidural simulation or ultrasonogram have been shown to accurately identify the caudal epidural space.12,13 Developmental defects have been reported commonly in the vertebral column to an extent of 3 $35 \% .{ }^{14}$ Spina bifida is a very important vertebral anomaly of which the commonest is spina bifida occulta. As the name suggests patients with spina bifida occulta will be asymptomatic and often the diagnosis will be either accidental or posthumous. Severe cases of spina bifida can be associated with number of disorders like intraspinal lipoma, tethered cord syndrome, genitourinary dysfunction, lumbar spondylolysis, foot deformities and syringomyelia.15 Additionally, spina bifida is one of the reasons for failure of caudal epidural block. Another clinical application of knowledge of sacral hiatus is required during the injection of corticosteroids in patients suffering from sciatica. ${ }^{16}$

\section{CONCLUSION}

Huge variability was observed in the shape, location and dimensions of sacral bones and sacral hiatus. It is important for the clinicians to keep in mind this variability while performing caudal epidural block.

\section{REFERENCES}

1. Sugar 0. How the sacrum got its name. JAMA 1987;257(15):2061-3.

2. Neil BR. The back. In: Susan S, Patrica C, Alan CR, et al. (eds). Gray's Anatomy the anatomical basis of clinical practice. $40^{\text {th }}$ edn. London: Churchill Livingstone Elsevier 2008:725-8.

3. Edwards WB, Hingson RA. Continuous caudal anesthesia in obstetrics. American Journal of Surgery 1942;57(3):459-64.

4. Nagashree MV, Pai V, Gireesh. An anatomical study of sacral hiatus in human dry sacra. Research Journal of Pharmaceutical, Biological and Chemical Sciences 2014;5(2):1195-9.
5. Patil DS, Jadav HR, Binodkumar, et al. Anatomical study of sacral hiatus for caudal epidural block. National Journal of Medical Research 2012;2(3):272-5.

6. Shewale SN, Laeeque M, Kulkarni PR, et al. Morphological and morphometrical study of sacral hiatus. International Journal of Recent Trends In Science And Technology 2013;6(1):48-52.

7. Shinde V, Bhusaraddi PS. A study of variations of sacral hiatus of dry human sacra in north interior Karnataka region. National Journal of Clinical Anatomy 2014;3(4):215-9.

8. Desai RR, Jadhav SD, Doshi MA, et al. Variations in the anatomical features of the sacral hiatus in Indian dry sacra. International Journal of Medical Research and Health Sciences 2014;3:634-8.

9. Sasikala P, Bilodi AS. Study of sacrum and its importance in epidural block. Int J Cur Res Rev 2015;7(9):28-32.

10. Wong SY, Li JY, Chen C, et al. Caudal epidural block for minor gynecologic procedures in outpatient surgery. Chang Gung Med J 2004;27(2):116-21.

11. Busoni P, Sarti A. Sacral intervertebral epidural block. Anaesthesiology 1987;67(6):993-5.

12. Chen CP, Tang SF, Hsu TC, et al. Ultrasound guidance in caudal epidural needle placement. Anesthesiology 2004;101(1):181-4.

13. Tsui BC, Tarkkila P, Gupta S, et al. Confirmation of caudal nee \& placement using nerve stimulation. Anesthesiology 1999;91(2):374-8.

14. Ali S, Azeemi AA. The prevalence of spinal bifida occulta in Pakistani population: a study of dry human sacra. Anaesth Pain \& Intensive Care 2014;18(2):157-61.

15. Gregerson DM. Clinical consequences of spina bifida occulta. J Manipulative Physiol Ther 1997;20(8):546-50.

16. Czarski Z. Treatment of sciatica with hydrocortisone and novocaine injection into the sacral hiatus. Przegl Lek 1965;21(7):511-13. 